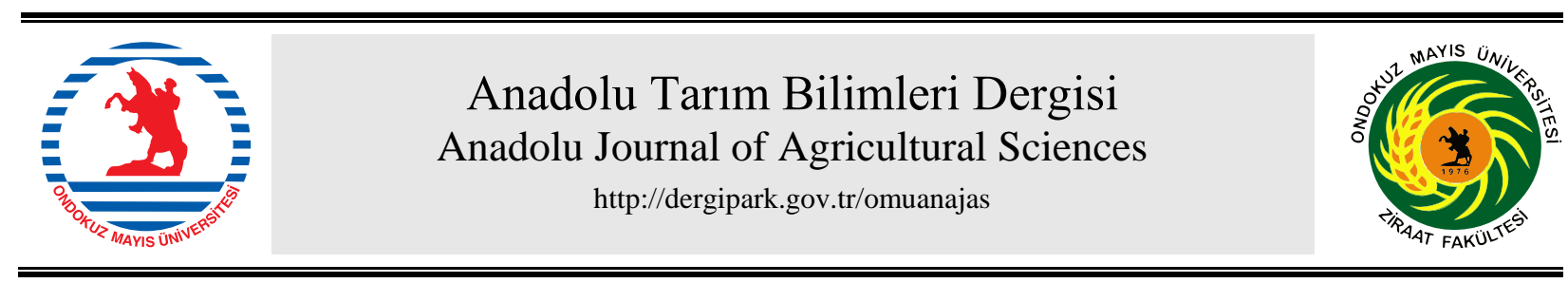

Araştırma/Research

Anadolu Tarım Bilim. Derg./Anadolu J Agr Sci, 35 (2020)

ISSN: 1308-8750 (Print) 1308-8769 (Online)

doi: $10.7161 /$ omuanajas.632156

\title{
Ulusal Dinamik Rüzgâr Erozyonu Modeli ve İzleme Sistemi Pürüzlülük Parametresinin Belirlenmesi
}

\author{
Reşat Akgöz $^{\mathrm{a}^{*}}$, Kenan İnce ${ }^{\mathrm{b}}$, Günay Erpul ${ }^{\mathrm{c}}$ \\ ${ }^{a, c}$ Ankara Üniversitesi, Ziraat Fakültesi, Toprak Bilimi ve Bitki Besleme Bölümü, Ankara, Türkiye \\ ${ }^{b}$ T.C. Tarım ve Orman Bakanlığı, Çölleşme ve Erozyonla Mücadele Genel Müdürlüğü, Ankara, Türkiye
}

*Sorumlu yazar/corresponding author: resatakgoz@gmail.com

Geliş/Received 11/10/2019 Kabul/Accepted 20/11/2019

\begin{abstract}
ÖZET
Ulusal boyutta rüzgâr erozyonunun tahmin edilebilmesi ve izlenmesi amaciyla, dinamik ve güncellenebilir veri tabanlarına sahip Yenilenmiş Rüzgâr Erozyonu Eşitliği [YREE] modelini esas alan Ulusal Dinamik Rüzgâr Erozyonu Modeli ve İzleme Sistemi (UDREMİS) geliştirilmiştir. İklim, toprak, topoğrafya, bitki örtüsü ve yönetim parametrelerinden oluşan YREE modeline ait topoğrafya ana faktörü içerisinde değerlendirilen pürüzlülük parametresinin belirlenmesine yönelik bilgiler bu yayında verilmektedir. Pürüzlülük parametresi, rüzgâr erozyonu içinde rüzgâr hızını azaltma ve hız profilini değiştirme konusunda büyük öneme sahiptir. Ulusal ölçekte rüzgâr erozyonunun değerlendirilmesinde kullanılan pürüzlülük parametresi, Çevresel Bilgilerin Koordinasyonu (COoRdination of INformation on the Environment-CORINE) arazi örtüsü/arazi kullanımı veri tabanı kullanılarak hesaplanmıştır. CORINE veri tabanında bulunan 44 sınıfa ek olarak 12 ülkesel sınıf 14 pürüzlülük sınıfı ile ilişkilendirilerek gerekli hesaplamalar yapılmıştır. Tüm ülke yüzeyi geliştirilen model ile 25 ha büyüklüğünde altıgenlere bölünmüş ve her bir altıgen içerisinde bulunan pürüzlülük sınıflarının alansal ortalamaları hesaplanarak her bir altıgen için bir pürüzlülük katsayısı hesaplanmıștır. Elde edilen bulgulara göre ortalama pürüzlülük parametresinin topoğrafyaya bağlı olarak Karadeniz, Akdeniz ve Ege gibi bölgelerde sirasıyla $0.39,0.33$ ve 0.32 olduğu, eğimin nispeten daha az olduğu Güney Doğu ve İç Anadolu gibi bölgelerde ise 0.14 olduğu belirlenmiştir.
\end{abstract}

\section{Determination of Roughness Parameter of National Dynamic Wind Erosion Model and Monitoring System}

\section{ABSTRACT}

The National dynamic wind erosion Equation (UDREMIS) has been developed to predict and monitor wind erosion at national level), based on the Revised Wind Erosion Equation (RWEQ) model with dynamic and updatable databases. This publication provides information on determining the roughness parameter which is evaluated within the topography main factor of RWEQ model consisting of climate, soil, topography, vegetation and management parameters. The roughness parameter is of great importance in reducing wind speed and changing speed profile within wind erosion. The roughness parameter used to evaluate wind erosion on a national scale was calculated using the Coordination of Information on the Environment-CORINE Land Cover/land use database. In addition to the 44 classes in the CORINE database, the required calculations were made by associating the 12-country class with the 14 roughness classes. The whole country surface was divided into 25 ha sized hexagons with the developed model and the area averages of the roughness classes in each hexagon were calculated and a roughness coefficient was calculated for each hexagon. According to the findings, the mean roughness parameter was found to be $0.39,0.33$ and 0.32 respectively in regions such as Black Sea, Mediterranean and Aegean, and 0.14 in regions such as South East and Central Anatolia, where the slope is relatively less.
Anahtar Sözcükler: CORINE

Pürüzlülük

Rüzgâr Erozyonu Yenilenmiş Rüzgâr Erozyonu Eşitliği (YREE)

Keywords: CORINE Roughness Wind Erosion Revised Wind Erosion Equation (RWEQ)

(C) OMU ANAJAS 2020 


\section{Giriş}

Doğal kaynakların sürdürülebilirliği ve yönetimi denildiğinde akla ilk gelen konulardan biri toprak erozyonu ve bunun çevreye olan etkileridir. Bilindiği üzere iklim, toprak, topografya ve bitki örtüsü birbirini bütünleyen ve yaşam döngüsünü organize eden en temel arazi unsurlarındandır. Bu nedenlerden dolayı insanoğlu farklı disiplinler altında, özellikle doğal kaynakların sürdürülebilir kullanımı ve gıda güvenliği ile bağdaşık olarak, yıllar boyu bu unsurların etkileşimini ve sonuçlarını araştırmıştır. Toprak erozyonu da bu etkileşimin bir sonucu olarak ortaya çıkmaktadır. Çeşitli kaynaklara göre ülkemizin \%90'ında kurak ve yarı kurak iklim koşulları hâkimdir. Topraklarımızın ancak $\% 14$ 'ünde organik madde kapsamı \%2'den fazladır, buna karş1 \%64'ünde bu oran \%1'in altındadır. Etkili toprak derinliğine bakılacak olursa, işlemeli tarıma elverişli olmayan arazilerin \%37.2 seviyelerinde olduğu bilinmektedir (Anonim 1978; Anonim 1987; Çanga ve Erpul 1994). Bütün bunlar göz önüne alındığında ülkemiz topraklarının erozyona duyarlılığının fazla olduğu ve yeterli koruma önlemi alınmazsa geri dönüşü olmayan evrelere girilebileceği söylenebilir.

Ülkesel ölçekte su ve rüzgâr erozyonu çalışmaları, Tarım ve Orman Bakanlığı'na bağlı Çölleșme ve Erozyonla Mücadele Genel Müdürlüğü (TOB ÇEMGM) bünyesinde son yıllarda ivme kazanmıştır. ÇEMGM tarafından yapılan değerlendirmelere göre ülkemizde çok şiddetli rüzgâr erozyonuna sahip toplam 1.292.771 ha alanın varlığ 1 tespit edilmiştir (İnce ve ark., 2019). Küresel iklim değişikliği ile birlikte ülkemizin daha kurak bir döneme gireceği ve iklimsel öngörülerin gerçekleşmesi durumunda rüzgâr erozyonu şiddeti ve etki alanının da artacağı ifade edilmektedir (Kömüşçü ve ark., 2003; Karaca ve ark., 2008;). Sürdürülebilir Toprak Yönetimi (STY) ve Sürdürülebilir Arazi Yönetiminin (SAY) benimsendiği ve büyük oranda uygulamaya konulduğu ülkelerde, bilimsel bilginin etkin k1lınması amaciyla toprak, su, topoğrafya ve bitki örtüsü kaynaklarının envanter çalışmalarının iyi bir biçimde ortaya konulduğu bilinmektedir. Kaldı ki söz konusu kaynakların planlanması ve bu kaynaklara bağlı toprak erozyonu tehlikesinin değerlendirilmesi ve izlenmesi için günümüz bilgi teknolojileri yeterli altyapıyı sağlamaktadır.

Türkiye'de son y1llarda ülke ölçeğinde veri setlerinin geliştirilmesi ile birlikte parsel ölçeğinden havza ve ülke ölçeğine doğru değişen boyutlarda erozyon tahminleri yapmak mümkün olmuştur. Özellikle rüzgâr erozyonuyla etkin mücadele edebilmek ve oluşabilecek zararları en aza indirmek amacıyla, öncelikle olası erozyon tehditlerinin doğru senaryolar altında tahmin edilmesi ve değerlendirmelerin noktasal değil bölgesel veya ülke ölçeğinde gerçekleştirilmesi gerekmektedir. Aynı zamanda SAY ve STY gibi kavramların önem kazandığı günümüzde, değişik konumsal ölçeklerde erozyon kontrol çalışmalarını planlamak, korumalı doğal kaynak kullanımını sağlamak, mühendislik çalışmalarında kullanılmak üzere bilimsel ve model tabanlı çalışmaların yapılması Türkiye'de bir zorunluluk haline gelmiştir (Erpul ve ark., 2016).

Son yıllara kadar yapılan çalışmalarda toprak erozyonu değerleri ve alanları ulusal ölçekte model yaklaşımla ortaya konulamamıştı. Ancak ÇEMGM tarafindan, RUSLE (Revised Universal Soil Loss Equation [Yenilenmiş Evrensel Toprak Kayıpları Eşitliği]) eşitliği esas alınarak su erozyonu sonucu taşınan sediment miktarını hesaplayan Dinamik Erozyon modeli ve İzleme Sistemi (DEMIS) kullanıma hazır hale getirilmiş ve elde edilen sonuçlar yayınlanmıştır (Erpul ve ark., 2018).

Aynı zamanda yine ÇEMGM tarafindan geliştirilen UDREMİS yardımıla ülkesel, nehir havzaları ve bölgesel ölçekte rüzgâr erozyonu ile meydana gelen toprak kayıları alansal ve zamansal olarak izlenebilir duruma gelmiştir. $\mathrm{Bu}$ yayında YREE modelinin ana faktörlerinden olan topografyaya bağlı pürüzlülük parametresinin elde edilmesine yönelik detaylı bilgi verilmektedir. Arazi pürüzlülük faktörü, rüzgâr hız ve profilini değiştirme konusunda büyük öneme sahiptir. Örneğin sırtlı toprak hazırlığında sırt yüksekliğinin $6 \mathrm{~cm}$ olması durumunda rüzgâr erozyonu sonucu taşınan sediment miktarının \%50 oranında azalması mümkün olup, sirtlı toprak hazırlığında da sırt yüksekliği ve sırt aralığ1 arasındaki mesafenin $1 / 4$ oranında korunmas1 gerektiği belirtilmiştir (Woodruff ve Siddoway, 1965). Hali hazırda uygulanmakta olan anızlı tarım, bitki artıklarının kullanılması, çiftlik gübresi uygulamaları gibi pek çok etkenin de amacının arazi pürüzlülüğünü arttırmaya yönelik olduğu uygulamacilar tarafindan bilinmektedir. Görünen odur ki pürüzlülük parametresi YREE modelinin en önemli unsurlarından biridir.

\section{Materyal ve Yöntem}

Ulusal ölçekte rüzgâr erozyonu sonucu taşınan sediment miktarını belirlemek amaciyla YREE modeli (Fryrear et al., 2000) dikkate alınarak güncellenebilir ve dinamik veritabanlarından oluşan UDREMIS sistemi 2016 yılında ÇEM tarafindan geliştirilmeye başlanmıştır. Geliştirilecek sistemin karar verici ve doğal kaynak yönetimi uzmanlarına alanda yapılacak çalışmalarda yol göstermesi, yapılan iyileştirmelerin sistem üzerinden izlenmesi hedeflenmiştir. 


\begin{tabular}{|c|c|c|c|c|c|}
\hline \multirow{2}{*}{$\begin{array}{c}\text { YREE } \\
\text { FAKTÖRÜ }\end{array}$} & \multicolumn{3}{|c|}{ DEĞİŞKEN } & \multirow[t]{2}{*}{ GÖSTERGE } & \multirow{2}{*}{$\begin{array}{c}\text { ÖLÇÜM } \\
\text { TEKNİĞİ }\end{array}$} \\
\hline & Simge & Değişken & Birim & & \\
\hline \multirow[t]{6}{*}{$\begin{array}{ll}\text { İklim } & \text { Faktörü } \\
\left(\mathrm{W}_{\mathrm{F}}\right) & \end{array}$} & $\mathrm{u}_{\mathrm{t}}$ & Rüzgâr hızı eşik değeri & $\mathrm{m} \mathrm{sn}^{-1}$ & $\begin{array}{l}\text { Rüzgâr h1z1, sıcaklık, } \\
\text { rüzgâr yönü }\end{array}$ & \multirow{6}{*}{$\begin{array}{l}\text { Otomatik } \\
\text { Meteorolojik } \\
\text { Gözlem } \\
\text { İstasyonu Verisi }\end{array}$} \\
\hline & $\mathrm{u}_{2}$ & Rüzgâr hızı & $\mathrm{m} \mathrm{sn}^{-1}$ & Rüzgâr h1z1 & \\
\hline & $\mathrm{E}_{\mathrm{TP}}$ & Potansiyel evapotrapirasyon & $\mathrm{mm}$ & $\begin{array}{l}\text { Rüzgâr hızı, sıcaklık, } \\
\text { solar radyasyon }\end{array}$ & \\
\hline & $\mathrm{R}_{\mathrm{d}}$ & Yağmurlu gün sayısı & gün & Yağış & \\
\hline & $\mathrm{R} \& \mathrm{I}$ & Yağış miktarı & $\mathrm{mm}$ & Yağ1ş & \\
\hline & SD & Kar yüksekliği & $\mathrm{cm}$ & Yağgiş & \\
\hline \multirow[t]{5}{*}{ Toprak Faktörü } & $\mathrm{OM}$ & Organik madde içeriği & $\%$ & Organik madde & \multirow[t]{5}{*}{$\begin{array}{l}\text { Toprak } \\
\text { Örneklemesi }\end{array}$} \\
\hline & Sc & Kil içeriği & $\%$ & Kil & \\
\hline & $\mathrm{Si}$ & Silt içeriği & $\%$ & Silt & \\
\hline & $\mathrm{Sa}$ & Kum içeriği & $\%$ & Kum & \\
\hline & $\mathrm{CaCO}_{3}$ & Kalsiyum karbonat içeriği & $\%$ & Kireç & \\
\hline \multirow{3}{*}{$\begin{array}{l}\text { Bitki Örtüsü } \\
\text { Faktörü }\left(\mathrm{C}_{\mathrm{OG}}\right)\end{array}$} & $\mathrm{S}_{\mathrm{LR}}$ & Artık kapalılığ1 & $\%$ & Bitki artığ1 & \multirow{3}{*}{$\begin{array}{l}\text { Vejetasyon } \\
\text { örneklemesi ve } \\
\text { izlenmesi }\end{array}$} \\
\hline & $\mathrm{S}_{\mathrm{LRS}}$ & Art1k boyu & $\mathrm{cm}$ & Bitki artığ1 & \\
\hline & $S_{\text {LRC }}$ & Bitki kapalılığg & $\%$ & Vejetasyon & \\
\hline \multirow{2}{*}{$\begin{array}{l}\text { Arazi Pürüzlülük } \\
\text { Faktörü }\left(\mathrm{K}_{\mathrm{tot}}\right)\end{array}$} & $\mathrm{R}_{\mathrm{R}}$ & Rastgele pürüzlülük & $\mathrm{cm}$ & \multirow{2}{*}{$\begin{array}{l}\text { Sirt yüksekliği ve } \\
\text { boşluğu }\end{array}$} & \multirow{2}{*}{$\begin{array}{l}\text { Pürüzlülük } \\
\text { örneklemesi ve } \\
\text { izlenmesi }\end{array}$} \\
\hline & $\mathrm{O}_{\mathrm{R}}$ & Doğrusal pürüzlülük & $\mathrm{cm}$ & & \\
\hline
\end{tabular}

Çizelge 1. YREE modeli, ana parametrelerine ait veri tabanları ve alt değişkenler

Table 1. RWEQ model, databases and sub variables of main parameters

YREE modeli parametreleri ülkesel ölçekte, ülkesel veri tabanları kullanılarak oluşturulmuştur (Çizelge 1 ve Şekil 1).

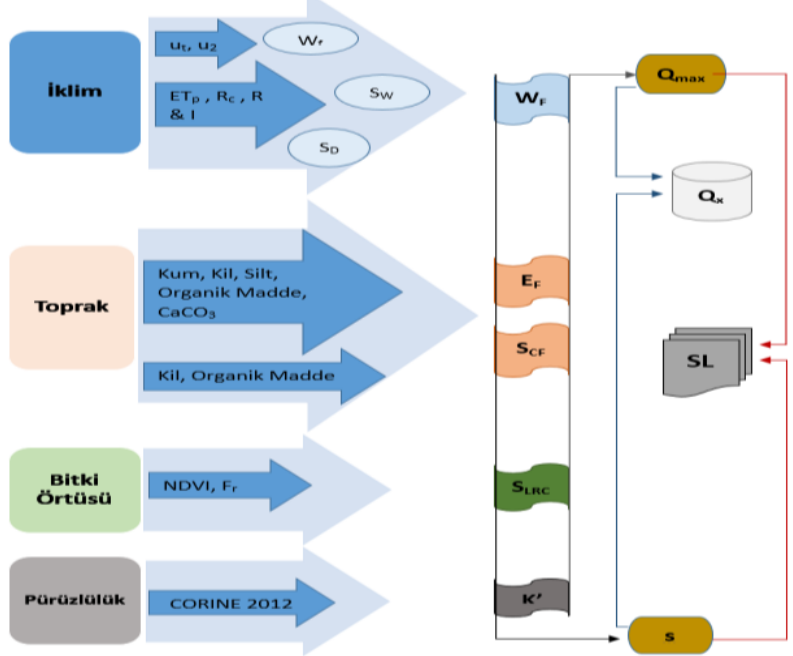

Şekil 1. YREE model yapısı eşitlik hesaplamaları akış şeması (İnce vd. 2019)

Figure 1. RWEQ model structure, flowchart

\section{1 Çalışma Alanı}

Rüzgâr erozyonunun genellikle yüzde altı (\% 6) ve altındaki eğimlerde düz ve düze yakın geniş alanlarda meydana geldiği kabulü bulunmaktadır (İnce ve ark., 2018). Bu maksatla tüm Türkiye'yi kapsayacak şekilde $\% 6$ ve altındaki eğime sahip alanlar Sayısal Yükseklik Modeline (SYM) (DEM: Digital Elevation Model) göre belirlenmiş̧ir. Yapılan değerlendirmeye göre (Şekil 2) Türkiye'de yaklaşık olarak 17 milyon ha alan $\% 6$ ve altındaki eğime sahip alanlar olarak ortaya konulmuştur.

Model bu alanlar kapsamında gerekli hesaplamaları yapmaktadır. Ancak diğer parametreler gibi pürüzlülük parametresinin de temelini oluşturan ve altı y1lda bir hazırlanan CORINE (2012) arazi örtüsü/arazi kullanım verileri ülkesel ölçekte üretildiği için pürüzlülük parametresi de ülkesel ölçekte ortaya konulmuştur. Böylece ülkesel ölçekte pürüzlülüğün yayılışı da değerlendirilmek istenmiştir.

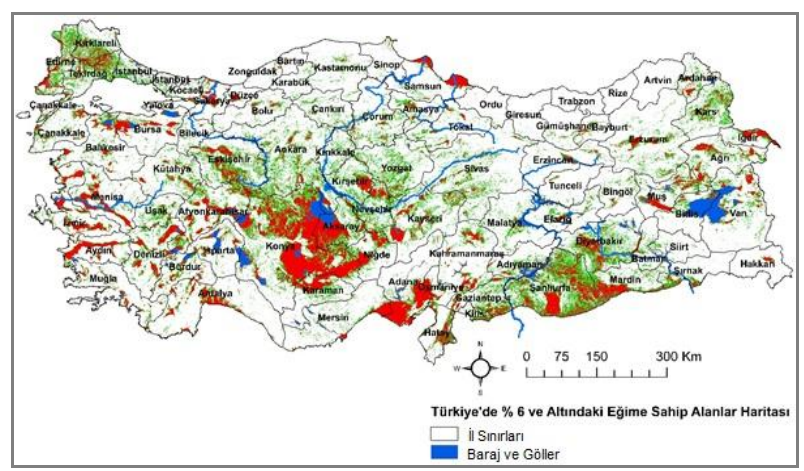

Şekil 2. Türkiye'de \%6 ve altındaki eğime sahip alanlar haritas1

Figure 2. Slope map of Turkey (sloping fields $\leq 6$ )

\subsection{CORINE Arazi Örtüsü ve Arazi Kullanımı Veritabant}

Çevresel Bilgilerin Koordinasyonu Projesi (Coordination of Information on the Environment, 
CORINE) Avrupa Birliği GMES (Global Monitoring for the Environment and Security) Çevre ve Güvenlik için Küresel İzleme programı kapsamındaki önemli arazi yönetimi projelerinden biridir.

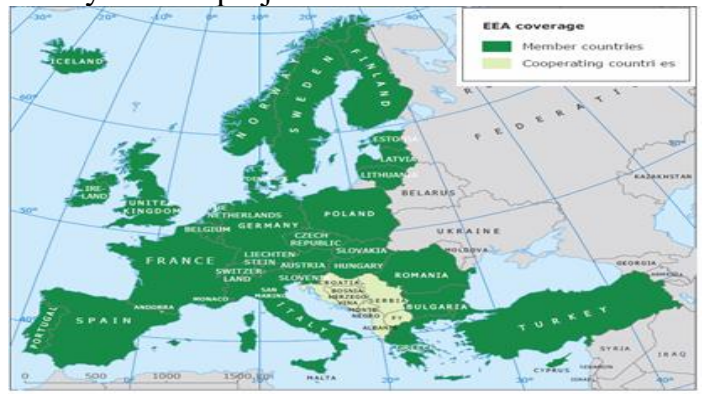

Şekil 3. CORINE projesinin uygulandığ ülkeler (29

üye, 6 aday ülke) http://www.eea.europa.eu)

Figure 3. CORINE project implemented countries (29

members, 6 candidate countries)

http://www.eea.europa.eu)

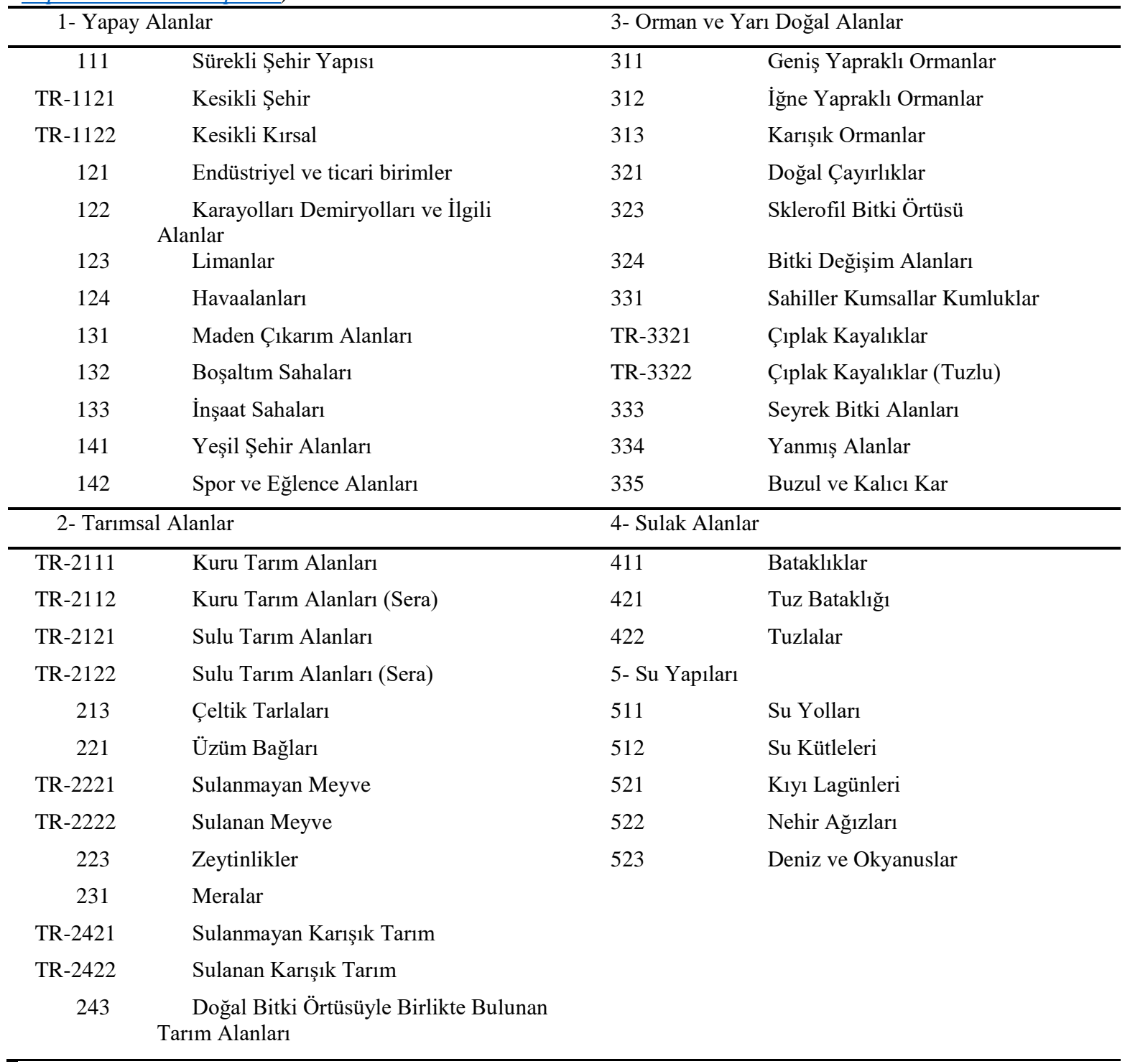

Çizelge 2. CORINE arazi örtüsü/arazi kullanımı sınıfları (http://www.eea.europa.eu)

Table 2. Corine land cover / land use classes (http://www.eea.europa.eu)
Projenin amaçlarından biriside Avrupa Çevre Ajansı kıstaslarına göre ülkelerin "Arazi Kullanım" haritalarının oluşturulması, bütün üye devletler için belirlenmiş öncelikli konulara göre çevrenin durumu ile ilgili bilgilerin toplanması, üye devletler içinde ya da uluslararası düzeyde, arazi ile ilgili bilgilerin uyumlu hale getirilmesidir(Bossard et al., 2000).

\subsection{CORINE Sinıflandırma Sistemi}

Avrupa Çevre Ajansı 5 adet temel (Şekil 4), 44 adet alt arazi kullanımı sınıfı belirlemiş ve Avrupa Birliği arazi örtüsünü bu sinıflar çerçevesinde şekillendirmiştir. Aynı zamanda ülkemize özgü olarak 12 adet TR adıyla 4. seviye sınıf kullanılmaktadır (Çizelge 2). 


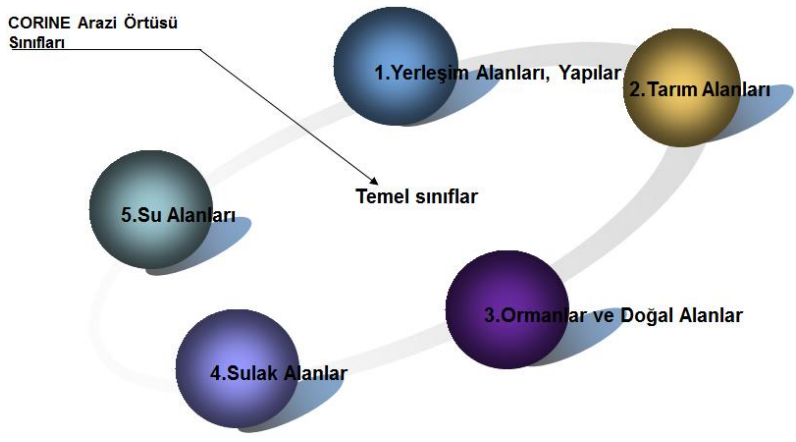

Şekil 4. CORINE arazi örtüsü temel 1. seviye sınıfları http://www.eea.europa.eu)

Figure 4. Corine land cover base 1. level classes http://www.eea.europa.eu)

\subsection{Pürüzlülük Değerlerinin CLC Veritabanı ile Eşleştirilmesi}

Arazi pürüzlülük değerlerinin arazi örtüsü değerleri ile eşleştirilebilmesi için arazi örtüsü sınıfları karakteristikleri dikkate alınarak 14 sınıfta toplanmıştır (Çizelge 3). Bilindiği üzere CLC projesi gerçekleştirilirken pürüzlülük ve pürüzlülük uzunluğu gibi unsurlar dikkate alınmamıştır. Ancak hem Avrupa'da hem de ülkemizde pürüzlülük verilerini elde edebilmek amacıyla ülke sathını örten bir veri tabanı olduğundan dolayı çeşitli bilimsel çalışmalar ile devşirilmiştir.

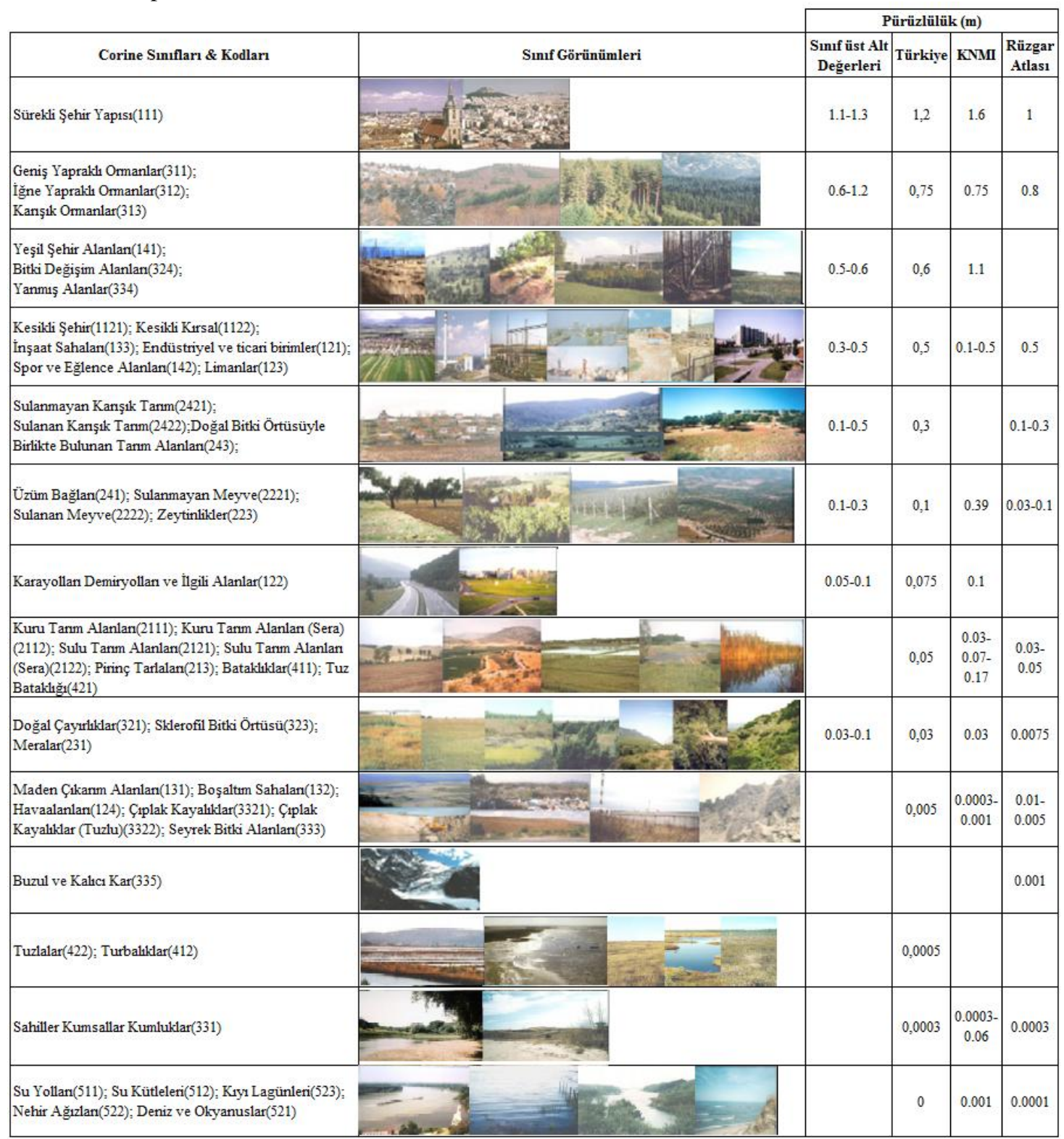

Çizelge 3. Türkiye, KNMI ve Rüzgâr Atlasında CLC sınıflarına ait kullanılan pürüzlülük değerleri (Silva, J. vd., $2007^{\prime}$ den faydalanılarak düzenlenmiştir)

Table 3. Roughness values used for CLC classes in Turkey, KNMI and Wind Atlas (Silva, J. et al., edited using 2007) 
Öncelikle Avrupa Rüzgâr Atlası çalışmalarında (Troen ve Peterson, 1989) CLC sinıfları ile rüzgâr pürüzlülük katsayıları arasındaki ilişki araştırılmış ve pürüzlülük sınıfları CLC sınıflarına bütünleşik hale getirilmiştir. Daha sonra ise pürüzlülük ve CLC sınıfı karşılaştırmaları ile Avrupa Rüzgâr Atlası çalışmalarında kullanılan değerlerin doğrulaması Hollanda Krallık Meteoroloji Enstitüsü (Royal Netherlands Meteorological Institute (KNMI) KNMI HYDRA Project. 1998) tarafından yapılmışıtır. Son olarak ise (Silva, J. et al., 2007) Portekiz ve İspanya'da CLC sınıfları ile pürüzlülük değerleri çalışılmış, pürüzlülük alt üst sınır değerleri belirlenmiştir (Painho, M. et al., 2005) (Çizelge 3).

Ülkemizde ise rüzgâr erozyonu sonucu taşınan sediment miktarının belirlenmesinde kullanılan pürüzlülük faktörü değerleri (Silva, J. et al., 2007) tarafından üretilen değerler esas alınarak gerekli hesaplamalar gerçekleştirilmiştir. Böylece YREE modeli için gerekli olan pürüzlülük değerleri UDREMIS veri tabanına işlenmiştir.

\subsection{Pürüzlülük Parametresinin Oluşturulması}

CLC projesinde en küçük poligon birimi 25 ha'dır. YREE modelinde pürüzlülük katmanı (Pürüzlülük yüzeyi) oluşturabilmek, alansal olarak büyük-küçük poligonları tekdüze bir desen haline getirebilmek için öncelikli olarak ülkemiz 25 ha'llk alan büyüklügünde altıgenlere bölünmüsstür. En küçük arazi kullanımı birimi 25 ha olduğu için bu büyüklük tercih edilmiştir. Avrupa da yapılan benzer çalışmalarda 25 ha'llk daireler kullanılmış, fakat dairelerin arasında kalan alanlarda veri kayıpları yaşanacağından dolayı ülkemizde altıgenler tercih edilmiştir.

Pürüzlülük katsayısı belirlenirken Şekil 5'de gösterildiği gibi her bir 25 ha'lık altıgen alanı içinde bulunan farklı arazi kullanım alanları, büyüklüklerine göre eşitlik 1 yardımıyla ağırlıklı olarak hesaplanmış ve tüm altıgenlere ait tek bir pürüzlülük katsayı değeri elde edilmiştir.

$$
q=\frac{\sum_{i=1}^{\mathrm{n}} K_{\mathrm{i}} A_{\mathrm{i}}}{\sum_{\mathrm{i}=1}^{\mathrm{n}} A_{\mathrm{i}}}
$$

Burada q, Ağırlıklı Pürüzlülük Katsayısı; K, Uygulama Alanındaki Pürüzlülük Katsayısı ve A, Uygulama Alanının Büyüklüğünü (ha) ifade etmektedir. $\mathrm{i}=1 \ldots \mathrm{n}$ ise uygulama alanı içerisindeki emsallerin dikkate alındığı alan büyüklüklerinin sayısını ifade etmektedir.

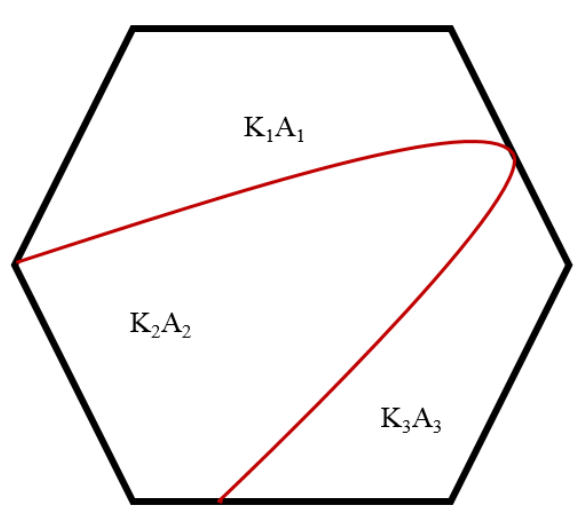

Şekil 5. YREE modeli pürüzlülük katsayısının belirlenmesinde kullanılan altıgen yaklaşım şeması Figure 5. RWEQ model hexagonal approximation scheme used to determine roughness coefficient

Altıgenlerin oluşturulmasında Coğrafi Bilgi Sistemleri (CBS) kullanılarak ArcGIS yardımıyla bu işe özgü bir model geliştirilmiştir.

Şekil 6'da da görüldüğü üzere ilgili modelin işletilmesiyle 3224744 adet 25 ha büyüklüğünde altıgen oluşturulmuştur. Daha sonraki aşamada geliştirilen yeni bir modelle, altıgenler ile CLC'den üretilen pürüzlülük katmanı çakıştırılarak, her bir altıgen içerisinde pürüzlülük sınıfı alanı ve $\%$ değerleri belirlenmiştir (Şekil 6). Şekil 6'de de görüldüğü üzere bu işlem sonrasında yaklaşı 5521006 satıllı çizelgesel bir veri oluşturulmuştur.

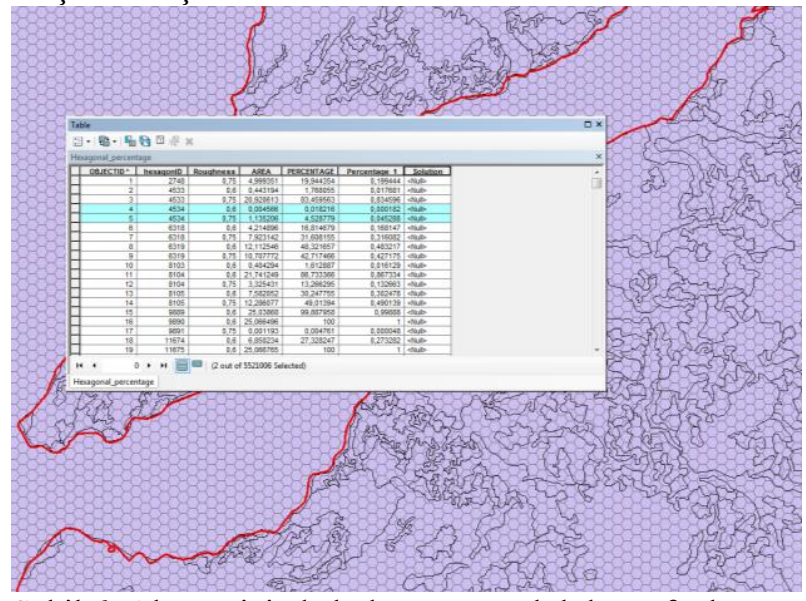

Şekil 6. Altıgen içinde bulunan pürüzlülük sınıfı alan ve oranlar1

Figure 6. Roughness class space and ratios found within the hexagon

Şekil 6' da görülen tablo üzerinde her bir altıgen içerisinde bulunan pürüzlülük sınıfının alansal ağırlıklı ortalaması hesaplanarak her bir altıgen için nihai pürüzlülük değerleri ortaya konmuştur. Çizelgesel veri ile altıgen haritasının yeniden birleştirilmesi sonucunda Şekil 7'de görülen altıgenler bazında tüm Türkiye için YREE pürüzlülük katmanı oluşturulmuştur. 


\section{Bulgular ve Tartışma}

Ülkesel ölçekte YREE modeli temelli UDREMIS sistemi için pürüzlülük parametresi CORINE 2012 arazi örtüsü/arazi kullanımı verileri kullanılarak hesaplanmıştır. Ülkesel ölçekte pürüzlülük parametresinin hesaplanmasinda CORINE 2012 veri tabanı büyük oranda kolaylık sağlamıştır. Bu çalışmada CORINE 2012 veri tabanının sağladığı en büyük avantaj ülke yüzeyini tek parçada kapatması ve standart bir sinıflandırma sistemine sahip olmasıdır.

Pürüzlülük parametresinde en büyük etken arazilerin yüzey kapalılığıdır. CORINE arazi örtüsü/arazi kullanımı haritaları üretilmesinde pürüzlülük ile ilgili bir standart gözetilmemesine rağmen arazi örtüsü doğrudan kapalılık ve dolaylı olarak pürüzlülükle ilgilidir. Haritada da görüldüğü üzere kapalılığın yüksek olduğu alanlarda pürüzlülük değeri de yüksektir. Kapalılığın fazla aynı zamanda pürüzlülüğünde yüksek olduğu alanlarda rüzgâr erozyonuna duyarlılık düşük olacaktır.

Coğrafi bölgeler düzeyinde pürüzlülük değerlerine bakılacak olunursa, pürüzlülüğün en düşük 0,13 ile Doğu Anadolu bölgesi daha sonra 0,14 ile İç Anadolu ve Güneydoğu Anadolu bölgelerinde olduğu belirlenmiştir (Çizelge 4). Doğu Anadolu bölgesinin alansal olarak çok büyük bir kısmı dağlık ve eğimli (\%6 ve üzeri) alanlardan oluşmaktadır. Ancak İç Anadolu ve
Güneydoğu Anadolu bölgelerimizin çok büyük bir bölümü düz ve düze yakın (eğim \%6'nın altında) alanlardan oluşmakla birlikte şu anda sürekli toprak işlemeye maruz kalan aktif tarım alanlarından oluşmaktadır. Toprak işleme, eğim ve pürüzlülük açısından bu alanların rüzgâr erozyonuna oldukça duyarlı olduğu ifade edilebilir.

$\begin{array}{cc}\text { COĞRAFİ BÖLGELER } & \text { ORTALAMA } \\ \text { PÜRÜZLÜLÜK DEĞERİ }\end{array}$

\begin{tabular}{cc}
\hline Akdeniz Bölgesi & 0.33 \\
Doğu Anadolu Bölgesi & 0.13 \\
Ege Bölgesi & 0.32 \\
$\begin{array}{c}\text { Güneydoğu Anadolu } \\
\text { Bölgesi }\end{array}$ & 0.14 \\
\hline
\end{tabular}

İç Anadolu Bölgesi

0.14

Karadeniz Bölgesi

0.39

Marmara Bölgesi

0.36

Çizelge 4. Coğrafi bölgelere göre ortalama pürüzlülük değerleri

Table 4. Average roughness values by geographic region

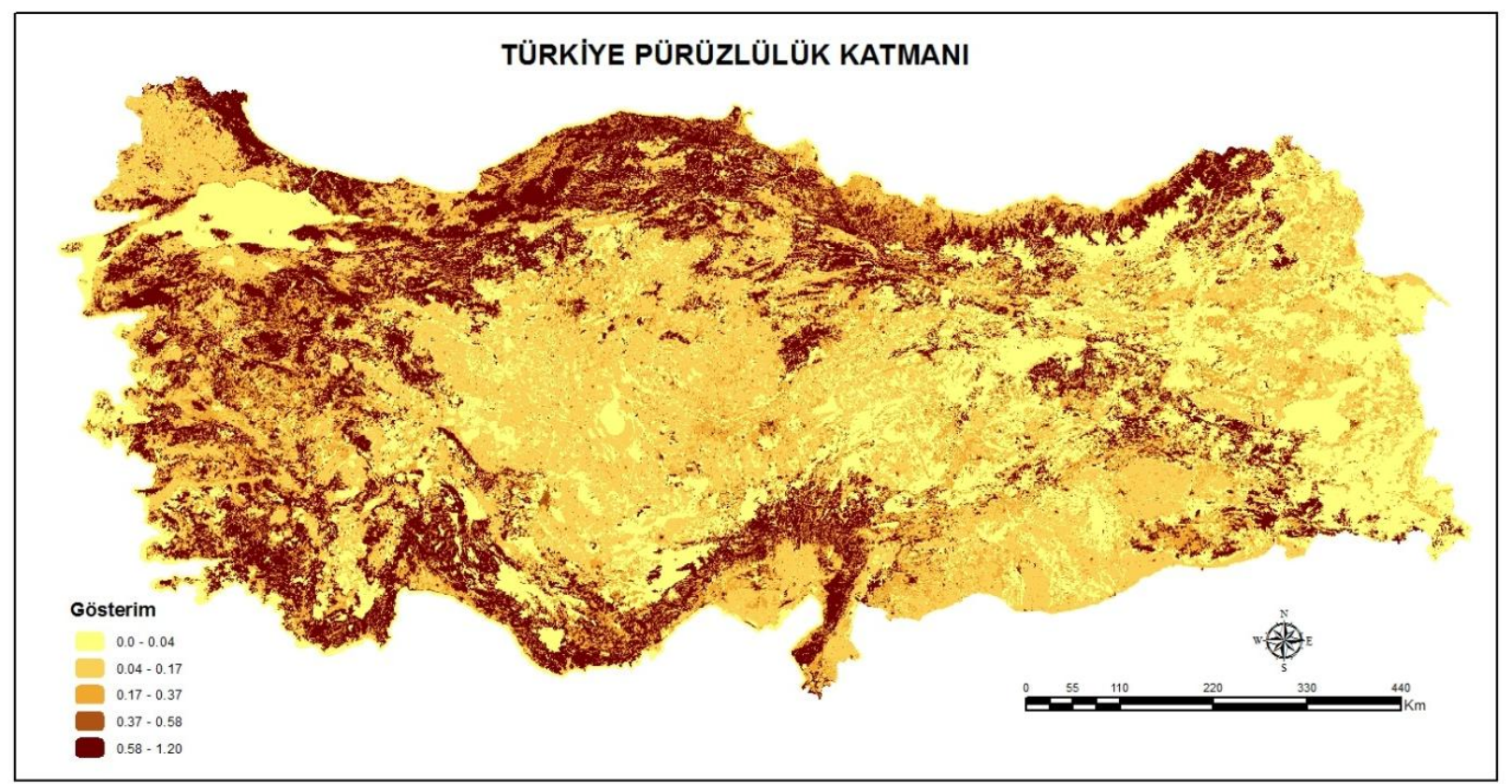

Şekil 7. Türkiye ölçeğinde YREE pürüzlülük katmanı

Figure 7. RWEQ roughness layer in Turkey

ÇEMGM tarafindan Türkiye'de rüzgâr erozyonu sonucu taşınan sediment miktarının belirlenmesine yönelik yapılan çalışmalarda da ortaya konulduğu üzere ana su havzalarına göre yapılan değerlendirmelerde çok şiddetli rüzgâr erozyonuna sahip havzaların Dicle-Fırat ile Kızılırmak ve Konya havzaları olduğu belirlenmişti (İnce vd., 2019). Buradan da görülebileceği üzere söz konusu havzaların Güney Doğu Anadolu, Doğu Anadolu ve İç Anadolu gibi ortalama pürüzlülük değerlerinin düşük bölgeler olduğu belirlenmiştir. Bir 
diğer ifade ile pürüzlülük değerinin düşük olmasının, rüzgâr erozyonu sonucu taşınabilecek sediment miktarını arttırdığg görülmektedir.

Pürüzlülük değerleri coğrafi bölgeler bazında alansal ve sınıfsal olarak değerlendirildiğinde ise Doğu Anadolu, Güneydoğu Anadolu ve İç Anadolu bölgelerinde en düşük pürüzlülük sınıfında bulunan alanların oranı çok yüksektir (Çizelge 5). Buda bu alanlarda rüzgâr erozyonunun yüksek olması önemli nedenlerindendir. Doğu Anadolu Bölgesinde ortalama eğimin yüksek olması rüzgâr erozyonunu büyük oranda kısıtlamaktadır. Ancak İç Anadolu ve Güneydoğu Anadolu Bölgeleri için eğim değerlerinin ortalamasının da düşük olmasından dolayı bu pürüzlülük değerleri ciddi oranda tehlike oluşturmaktadır. Bu iki bölgemizin, Türkiye'nin en önemli tarım alanlarına sahip olduğu düşünüldüğünde sürekli artan nüfusumuzun gıda ihtiyacını karşılayabilmemiz için SAY-STY politikalarının bu gibi alanlarda katı bir şekilde uygulanmas1 gerekmektedir.

\begin{tabular}{lccccc}
\hline \multicolumn{1}{c}{ COĞRAFİ } & & Pürüzlülük & Sinıflar1 & & \\
BÖLGELER & $0,0-0,04$ & $0,04-0,17$ & $0,17-0,37$ & $0,37-0,58$ & $0,58-1,20$ \\
\hline Akdeniz & $1.629 .726,14$ & $1.861 .516,38$ & $1.556 .637,06$ & $1.225 .828,59$ & $2.717 .646,7$ \\
\hline Doğu Anadolu & $7.090 .391,09$ & $3.353 .559,6$ & $2.168 .023,08$ & $662.944,92$ & $847.623,7$ \\
\hline Ege & $1.151 .171,76$ & $2.353 .464,33$ & $1.803 .454,06$ & $1.263 .291,55$ & $2.337 .662,32$ \\
\hline Güneydoğu Anadolu & $2.608 .138,98$ & $3.268 .253,99$ & $1.386 .711,77$ & $467.271,6$ & $591.622,64$ \\
\hline İç Anadolu & $5.326 .638,61$ & $8.317 .459,25$ & $2.616 .999,9$ & $965.117,44$ & $1.366 .353,76$ \\
\hline Karadeniz & $1.352 .348,73$ & $2.210 .112,12$ & $2.132 .819,34$ & $1.752 .566,28$ & $4.314 .971,54$ \\
\hline Marmara & $325.025,35$ & $2.323 .056,95$ & $1.222 .722,99$ & $1.035 .781,21$ & $2.399 .193,38$ \\
\hline Toplam Alan (ha) & $19.483 .440,7$ & $23.687 .422,6$ & $12.887 .368,2$ & $7.372 .801,59$ & $14.575 .074,1$ \\
\hline
\end{tabular}

Çizelge 5. Coğrafi bölgelere göre ortalama pürüzlülük sınıfsal ve alansal dağılımı

Table 5. Average roughness class and area distribution by geographic region

\section{Sonuç}

CBS ve veri tabanı yönetim sistemlerinin etkileşimli bir şekilde kullanılması ile YREE model yapısına göre pürüzlülük parametresi belirlenmiştir. Ülkemiz koşullarında belirli dönemler halinde dinamik şekilde güncellenecek veri tabanları yardımıyla rüzgâr erozyonunun zamansal ve mekânsal değişimi izlenebilecektir. Topoğrafya ana parametresi altında değerlendirilen pürüzlülük faktörü de YREE modelini esas alan UDREMIS yazılımına dinamik, güncellenebilir şekilde kurgulandığından dolayı kolaylıkla bütünlenmiş hale getirilmiştir.

CORINE projeleri Avrupa Çevre Ajansının uyguladığı stratejiye göre 6 yılda bir güncellenmektedir. Projemizde pürüzlülük parametresi olarak CORINE 2012 verileri kullanılmıştır. Önümüzdeki süreçte ise CORINE 2018 projesi tamamlandığında, güncel CORINE 2018 pürüzlülük parametresi üretilerek UDREMIS yazılımına bütünleşik bir hale getirilecektir.

YREE modelinin tüm parametreleri pürüzlülük parametresi ile birlikte zamansal ve mekânsal ölçeklerde elde edilmiştir. UDREMIS yazılımının kullandığ 1 analitik veri altlıkları sayesinde rüzgâr erozyonuna bağlı arazi tahribatının görüldüğü alanlarda niceliksel olarak sonuçlar alınabilmektedir. Böylece STY ve SAY bakımından arazi kullanımı planlamalarının yapılabilmesi için büyük öneme sahip altlıklar sağlanmıştır.

\section{Teșekkür}

Bu çalışmayı destekleyen resmi yada özel kuruluş varsa belitrilmelidir.

\section{Kaynaklar}

Anonim, 1978. Türkiye Arazi Varlığı. Toprak Su Genel Müdürlüğü. Ankara.

Anonim, 1987. Türkiye Genel Toprak Amenajman Planlaması. Köy Hizmetleri Genel Müdürlügü, Ankara.

Anonim, 1982. Türkiye Genel Toprak Haritası Sayısal Toprak Veritaban1. Türkiye Toprak ve $\mathrm{Su}$ Kaynakları Ulusal Bilgi Merkezi (UBM) Köy Hizmetleri Genel Müdürlüğü, Ankara.

Bossard, M., Feranec, J., Otahel J., 2000. CORINE land cover technical guide - addendum 2000; European Environment Agency; Copenhagen.

Çanga, M., Erpul, G., 1994. Toprak işlemeli Tarım Alanlarında Erozyon ve Kontrolü. Topraksu, 3(2), 14-16.

Erpul G., Şahin S., Akgöz R., İnce K., Güden A., Çetin E., 2016. Türkiye Yağışlarının Özellikleri ve Yenilenmiş Evrensel Toprak Kayıpları Eşitliği (YETKE) R Faktörü. Çölleşme ve Erozyonla Mücadele Genel Müdürlüğü Yayınları. s:10-22, Ankara.

Erpul, G., Şahin, S., İnce, K., Küçümen, A., Akdağ, M.A., Demirtaş, İ., Çetin, E., 2018. Türkiye Su 
Erozyonu Atlası. Çölleşme ve Erozyonla Mücadele Genel Müdürlüğü Yayınları. Ankara

European Environmental http://www.eea.europa.eu (Erişim tarihi: $01.10 .2019)$

Fryrear D.W., Bilbro J.D., Saleh A., Schomberg H., Stout J.E., Zobeck T.M., 2000. RWEQ: improved wind erosion technology. Journal of Soil and Water Conservation 55: 183-189.

Fryrear D.W., Saleh A., Bilbro J.D., Schomberg H.M., Stout J.E., Zobeck T.M., 1998. Revised Wind Erosion Equation (RWEQ). Technical Bulletin 1, Southern Plains Area Cropping Systems Research Laboratory, Wind Erosion and Water Conservation Research Unit, USDA-ARS.

İnce K., Akgöz R., Erpul G., 2019. Türkiye'de Rüzgâr Erozyonu Nedeniyle Oluşan Toprak Kayıplarının Model Tabanlı Mekânsal ve Zamansal Değişiminin Belirlenmesi. Iğdır Üniversitesi Fen Bilimleri Enstitüsü Dergisi, Basım aşamasında.

İnce, K., Çelik, S., Erpul, G. 2019. Determination and Mapping of Wind Erosion Soil Susceptibility Variables at the National Scale in Turkey, Ege Univ. Ziraat Fak. Derg., 56 (1):109-120, DOI:10.20289/zfdergi.455581

İnce, K., Şahin, S., Erpul, G., 2018. Yenilenmiş Rüzgâr Erozyonu Eşitliği İklim Faktörünün Ulusal Ölçekte Belirlenmesi. Toprak Su Dergisi, 7 (2), 12-20. DOI: 10.21657/topraksu.460715 (ISSN: 2146-7072 (print) e-ISSN: 2148-5534).

Karaca, A., Öztürk, H. S., Bayramin, L, Erpul, G., Suiçmez, B.K. 2008. Küresel isınma ve ülkemiz tarımına etkileri. Türktarım, Tarım ve Köyişleri Bakanlığı Dergisi, 179. S. 24-29.

Kömüşçü, A. Ü., Dorum, A., ve Ceylan, A., 2003. Yağış Şiddeti ve Tekerrür Sürelerine Göre Sel ve Taşkın
Riski Analizi. JJJ. Atmosfer Bilimi Sempozyumu, s. 28-36.

Painho, M. and Caetano, M., 2005. Cartografia de ocupação do solo: Portugal continental, 1985-2000; Corine Land Cover 2000; Instituto do Ambiente, Amadora.

Royal Netherlands Meteorological Institute; http://www.knmi.nl (Erişim tarihi: 01.10.2019)

Silva, J., Ribeiro, C., Guedes, R., 2007. Roughness Length Classification of Corme Land Cover Classes. Megajule. Pt. S.10.

Troen, I. and Petersen, E.L., 1989. European Wind Atlas; Commission of the European Communities; Riso National Laboratory, Roskilde.

Woodruff N.P. and Siddoway F.H., 1965. A wind erosion equation. Soil Science Society of America Journal. Proc. Vol 29; pp 602-608. 